\title{
FAC-SEM using PLS-SEM: An empirical illustration in a customer value measurement context
}

\author{
Regular Paper Submission
}

\author{
Sandra Streukens \\ Hasselt University \\ sandra.streukens@uhasselt.be
}

\author{
Sara Leroi-Werelds \\ Hasselt University \\ sara.leroiwerelds@uhasselt.be
}

\begin{abstract}
FAC-SEM is a special type of multigroup analysis where the groups are structured as a factorial design. The aim of FAC-SEM is to assess how the path model parameters vary as a function of the dimensions of the underlying factorial design. As such, FAC-SEM offers researchers a unique opportunity to further understand their experimental data. This paper explains how the FAC-SEM methodology can be used in a PLS path modeling context and demonstrates the procedure using empirical data from a customer value measurement study.
\end{abstract}

Keywords: FAC-SEM, factorial designs, PLS-SEM, multigroup analysis, customer value, marketing.

\section{Introduction}

Factorial structural equation models (FAC-SEM) enable researchers to assess how relationships in a model vary as a function of an underlying factorial design. The most evident way to understand the purpose of FAC-SEM is to compare it to ubiquitously used ANOVA models. Whereas the aim of ANOVA is to statistically assess mean differences arising from a factorial design, FAC-SEM uses structural model parameters instead. Therefore, FAC-SEM can also be regarded as a specific type of moderator analysis in which the moderators follow the structure of a factorial design.

The FAC-SEM methodology as originally developed by Iacobucci, Grisaffe, Duhanchek, and Marcati (2003) offers a rich opportunity to obtain a deeper understanding of experimental data. So far, the FAC-SEM methodology has only been developed and demonstrated using covariance-based SEM. The aim of this paper is to demonstrate how the FAC-SEM methodology can be applied using PLS-SEM.

To assess the abovementioned objective, this paper proceeds as follows. First, we explain in detail the FAC-SEM methodology and how it can be applied using PLS-SEM. Second, we provide a description of the empirical study that will be used to demonstrate the proposed methodology. Third, we describe the FAC-SEM analysis and explain the accompanying analytical results.

\section{The FAC-SEM Methodology}

\subsection{Factorial designs}

A factorial design is a statistical experimental design used to assess the effects of two or 
more independent variables (i.e., factors) at various levels. The treatment conditions in a factorial design are combinations of the factor levels. Furthermore, the arrangement of the treatment conditions is such that information can be obtained about the influence of each of the factors separately (i.e., main effects) and about how the factors combine to influence relevant outcomes (i.e., interaction effects). In the remainder of our explanation of the FACSEM methodology we use a factorial design consisting of two factors (i.e., $A$ and $B$ ), each having two levels (i.e., $a_{1}, a_{2}, b_{1}$, and $b_{2}$ ). As shown graphically in Figure 1 panel A below, this design results in four cells (i.e., $a_{1} b_{1}, a_{1} b_{2}, a_{2} b_{1}$, and $a_{2} b_{2}$ ). Typically ANOVA techniques are used to assess how a construct's mean value differs as a result of the factors making up the factorial design (see also Figure 1 panel B).

\subsection{FAC-SEM: Factorial designs and differences in model parameters}

Originally developed by Iacobucci et al. (2003), FAC-SEM involves a multigroup approach to structural equation modeling in which the different groups represent the different cells of a factorial design. In contrast to the cell means in ANOVA, the cells in case of FACSEM contain path model parameters describing the nomological net among different constructs (see also Figure 1 panel C). The purpose of FAC-SEM is to statistically test whether and how the structural model parameters vary significantly as a function of the underlying factorial design. Similar to ANOVA, FAC-SEM involves testing factors' main and interaction. In the context of FAC-SEM main effects refer to differences in structural model parameters across different levels of a factor, while remaining the influence of the other factor(s) constant. Interaction effects are present when the main effect of one factor is not constant across levels of the other factor(s) in the factorial design. Table 1 below summarizes the hypotheses that can be tested using the FAC-SEM methodology and compares them with the traditional ANOVA hypotheses.

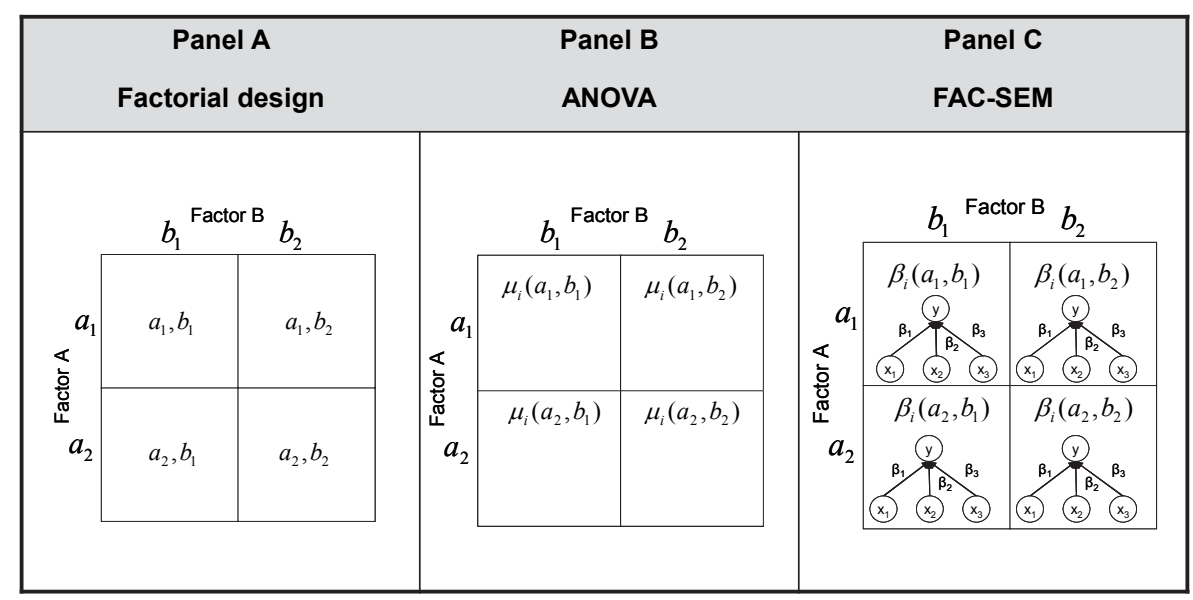

Figure 1: Factorial designs, ANOVA and FAC-SEM 
Table 1: General format FAC-SEM hypotheses

\begin{tabular}{|c|c|c|}
\hline Hypotheses in general terms & ANOVA hypotheses & FAC-SEM hypotheses \\
\hline $\begin{array}{l}\mathrm{H}_{0} \text { : Factor A does not have an impact on the magnitude of } \\
\text { the statistic } \\
\mathrm{H}_{\mathrm{a}} \text { : Factor A has an impact on the magnitude of the statistic }\end{array}$ & $\begin{array}{l}H_{0}: \mu_{i}(1 \cdot)=\mu_{i}(2 \cdot) \\
H_{a}: \mu_{i}(1 \cdot) \neq \mu_{i}(2 \cdot)\end{array}$ & $\begin{array}{l}H_{0}: \beta_{i}(1 \cdot)=\beta_{i}(2 \cdot) \\
H_{a}: \beta_{i}(1 \cdot) \neq \beta_{i}(2 \cdot)\end{array}$ \\
\hline $\begin{array}{l}\mathrm{H}_{0} \text { : Factor } \mathrm{B} \text { does not have an impact on the magnitude of } \\
\text { the statistic } \\
\mathrm{H}_{\mathrm{a}} \text { : Factor B has an impact on the magnitude of the statistic }\end{array}$ & $\begin{array}{l}H_{0}: \mu_{i}(\cdot 1)=\mu_{i}(\cdot 2) \\
H_{a}: \mu_{i}(\cdot 1) \neq \mu_{i}(\cdot 2)\end{array}$ & $\begin{array}{l}H_{0}: \beta_{i}(\cdot 1)=\beta_{i}(\cdot 2) \\
H_{a}: \beta_{i}(\cdot 1) \neq \beta_{i}(\cdot 2)\end{array}$ \\
\hline $\begin{array}{l}\mathrm{H}_{0}: \text { Factor A's impact on the magnitude of the statistics } \\
\text { does not depends on Factor B } \\
\mathrm{H}_{\mathrm{a}} \text { : Factor A's impact on the magnitude of the statistics } \\
\text { depends on Factor B }\end{array}$ & $\begin{array}{l}H_{0}: \mu_{i}(11)-\mu_{i}(12)=\mu_{i}(21)-\mu_{i}(22) \\
H_{a}: \mu_{i}(11)-\mu_{i}(12) \neq \mu_{i}(21)-\mu_{i}(22)\end{array}$ & $\begin{array}{l}H_{0}: \beta_{i}(11)-\beta_{i}(12)=\beta_{i}(21)-\beta_{i}(22) \\
H_{a}: \beta_{i}(11)-\beta_{i}(12) \neq \beta_{i}(21)-\beta_{i}(22)\end{array}$ \\
\hline
\end{tabular}

\subsection{Testing FAC-SEM hypotheses}

The first step in testing the FAC-SEM hypotheses is to assess whether the structural model parameters are indeed different across the cells of the factorial design (i.e., $H_{0}: \beta_{i}(11)=\beta_{i}(12)=\beta_{i}(21)=\beta_{i}(22)$. To test this hypothesis Sarstedt, Henseler, and Ringle's (2011) omnibus test of group differences can be used. Upon rejection of the omnibus null hypothesis, the researcher proceeds by assessing the existence of interaction and main effects by conducting a series of multigroup analyses.

To test whether an interaction effect exist, the bootstrap estimates obtained in testing the omnibus test are used to construct percentile confidence intervals to test the null hypothesis whether the difference in parameter estimates stemming from one factor remain unaffected by the other factor of the design (i.e., $\left.H_{0}: \beta_{i}(11)-\beta_{i}(12)=\beta_{i}(21)-\beta_{i}(22)\right)$.

Testing for the existence of the factors' main of effects involves regrouping the data and re-estimating the model. As can be concluded from the FAC-SEM hypotheses in Table 1 above, testing a factor's main effect involves aggregating the data over other factor's different levels. In terms of Figure 1 panel $\mathrm{C}$, to test whether the model parameters vary as a function of factor A (i.e., main effect factor A) the data over cells $a_{11}$ and $a_{12}$ are merged into a single group $a_{1}$ and the data over cells $a_{21}$ and $a_{22}$ are merged into a single group $a_{2}$. To test the null hypothesis concerning factor A's main effect (i.e., $H_{0}: \beta_{1 .}=\beta_{2}$.) the confidence set approach suggested by Sarstedt et al. (2011) can be used. Note that for addressing the null hypothesis concerning factor B's main effect this procedure needs to be repeated.

\section{Empirical Illustration FAC-SEM using PLS-SEM ${ }^{1}$}

\subsection{Background and purpose of the study}

Customer value has been of continuing interest to marketing researchers and practitioners alike. Moreover, it has been recognized as one of the most significant factors in the success of

\footnotetext{
${ }^{1}$ This empirical illustration is part of a study of which a part has already been published (i.e., Leroi-Werelds et al. 2014). Due to space limitations and our focus in the current paper on the FAC-SEM approach rather than the associated marketing contents we opted not to repeat details of the published part of the study, but refer to it whenever applicable.
} 
organizations (Slater, 1997). In line with Zeithaml's (1988, p. 4) definition that "perceived value is the consumer's overall assessment of the utility of a product based on perceptions of what is received and what is given", there has been a general consensus that customer value involves a trade-off between benefits and costs. Given the academic and practical relevance of perceived customer value, there is a pressing need for further understanding of how this construct should be measured (e.g., Sánchez-Fernández, Iniesta-Bonillo, \& Holbrook, 2009).

Over the years several value measurement methods have been put forward in the literature, all using Zeithaml's definition as point of departure In general, the value measurement methods of Dodds, Monroe, and Grewal (1991), Gale (1994), Woodruff and Gardial (1996), and Holbrook (1999) dominate the marketing literature. Although all of these methods have their merits, considerable differences among them exist. One key domain of difference involves the nature of the benefits and costs included in the model differs across the value conceptualizations. Following Gutman's (1982) means-end chain model, these can be measured at the attribute and/or consequence level. Attributes are concrete characteristics or features of a product or service such as size, shape or on-time delivery. Consequences are more subjective experiences resulting from product use such as a reduction in lead time or a pleasant experience (Gutman 1982).

In a large-scale empirical study Leroi-Werelds, Streukens, Swinnen, and Brady (2014) compared the predictive ability of four commonly used perceived customer value measurement methods (i.e., Dodds et al. (1991); Gale (1994); Woodruff \& Gardial (1996); Holbrook (1999). As can be seen in Table 2, the superiority in predictive ability of these value measurement methods in terms of customers' word of mouth intentions is not consistent across settings that differ in terms of involvement (high-low) and type of offering (feel-think). To examine whether a structural pattern can be discerned among these differences in predictive ability we will proceed by examining whether the underlying factorial design implied by the use of the FCB matrix (level of involvement * type of offering) moderates the relative performance of the value measurement methods

Table 2: Predictive ability value measurement methods in terms of word-of-mouth

\begin{tabular}{|c|c|c|c|c|c|c|c|c|c|}
\hline \multicolumn{5}{|c|}{$\begin{array}{c}\text { Toothpaste } \\
\text { (Think - Low involvement) }\end{array}$} & \multicolumn{5}{|c|}{$\begin{array}{c}\text { DVD player } \\
\text { (Think-High involvement) }\end{array}$} \\
\hline & D & G & W & H & & D & $\mathbf{G}$ & W & H \\
\hline D & & & & & D & & & & \\
\hline G & & $.61(.37)$ & & $*$ & $\mathbf{G}$ & & $.76(.58)$ & & $* *$ \\
\hline $\mathbf{W}$ & & & $.63(.40)$ & & $\mathbf{W}$ & & & $.76(.58)$ & $* *$ \\
\hline $\mathbf{H}$ & & $*$ & & $.72(.52)$ & $\mathbf{H}$ & & $* *$ & $* *$ & $.62(.38)$ \\
\hline \multicolumn{5}{|c|}{$\begin{array}{c}\text { Soft drink } \\
\text { (Feel - Low involvement) }\end{array}$} & \multicolumn{5}{|c|}{$\begin{array}{c}\text { Day cream } \\
\text { (Feel-High involvement) }\end{array}$} \\
\hline & D & $\mathbf{G}$ & W & H & & D & G & $\mathbf{W}$ & H \\
\hline D & $.60(.36)$ & & & & D & $.56(.32)$ & & $* *$ & \\
\hline $\mathbf{G}$ & & $.58(.33)$ & & & $\mathbf{G}$ & & $.60(.36)$ & $*$ & \\
\hline $\mathbf{W}$ & & & $.59(.35)$ & & $\mathbf{W}$ & $* *$ & $*$ & $.73(.54)$ & \\
\hline $\mathbf{H}$ & & & & $.62(.39)$ & $\mathbf{H}$ & & & & $.64(.41)$ \\
\hline
\end{tabular}

Notes: This table displays the R-values with the $\mathrm{R}^{2}$-values in parenthesis. $\mathrm{D}=$ Dodds; $\mathrm{G}=\mathrm{Gale} ; \mathrm{W}=$ Woodruff and Gardial; $\mathrm{H}=$ Holbrook. ${ }^{*} p<.10 * * p<.05$

\subsection{Underlying factorial design}

The FCB grid classifies customers' purchase decisions on two dimensions: involvement and type of offering. Involvement is defined as the attention of a customer to a product or a service 
because it is somehow important or relevant to him (Ratchford, 1987). Regarding the type of offering, the FCB grid discerns between think and feel offerings. Think offerings are products or services bought to satisfy utilitarian needs, while feel offerings represent products and services bought to satisfy emotional wants.

\subsection{Hypothesis development}

As mentioned in paragraph 2.2, FAC-SEM allows for the testing of both main and interaction effects. Below we therefore develop hypotheses reflecting the main of effects of involvement (H1) and type of offering $(\mathrm{H} 2)$ as well as the interaction effect between involvement and type of offering (H3). In terms of structural model parameters, the hypotheses focus on the structural relationships between on the one hand perceived customer value and on the other hand word-ofmouth intent. That is, we are interested in the predictive ability of perceived customer value as measured by the different approached in terms of word-of-mouth intent.

According to consumer research (e.g., Mulvey and Olson (1994), Claeys, Swinnen, and Abeele (1995)) the level of involvement and the type of product (feel-think) influence customers' means end chains. Mulvey and Olson (1994) show that the higher the level of involvement, the more a person is aware of the consequences that stem from product use. Likewise, research by Claeys et al. (1995) reveals that, compared to think products, the means-end chains for feel products are characterized by a higher level of abstraction.

A key dimension of difference among the four commonly used value measurement methods is the extent to which they assess customer value perceptions at the attribute or consequence level. On the one methods proposed by Holbrook (1999) and Woodruff and Gardial (1996) take into the consequences customers experience from product use, whereas the other methods do not this. On the basis of this theoretical foundation, we conjecture that the relative performance of value measurement methods is influenced by the degree of correspondence between the level of abstraction of the benefits and sacrifices assessed by the value measurement method and the characteristics of the means-end chains that depend on the level of involvement and the type of product. This leads to the following hypotheses:

H1: $\quad$ The difference in performance (i.e., predictive ability in terms of word of mouth intent) between value measurement methods that assess benefits and sacrifices at the consequence level (i.e., Woodruff \& Gardial and Holbrook) and value measurement methods that do not assess benefits and sacrifices at the consequence level (i.e., Gale and Dodds et al.) is larger for high involvement offerings than for low involvement offerings.

H2: $\quad$ The difference in performance i.e., predictive ability in terms of word of mouth intent) between value measurement methods that assess benefits and sacrifices at the consequence level (i.e., Woodruff \& Gardial and Holbrook) and value measurement methods that do not assess benefits and sacrifices at the consequence level (i.e., Gale and Dodds et al.) is larger for feel offerings than for think offerings.

Furthermore, Claeys et al. (1995) infer that under a high level of involvement the difference between think and feel offerings may become more prominent, because under high involvement conditions, the cognitive structure is better organized at the product-knowledge levels (i.e., the attributes) and the self-knowledge levels (i.e., the consequences). Accordingly, we propose the following hypothesis.

H3: In terms of the relative performance (i.e., predictive ability in terms of word of mouth intent) of value measurement methods that assess benefits and sacrifices at the consequence level (i.e., Woodruff \& Gardial and Holbrook) and value measurement 
methods that do not assess benefits and sacrifices at the consequence level (i.e., Gale and Dodds et al.), the difference in relative performance for feel and think products will be more pronounced in case of a high level of involvement than in case of a low level of involvement.

\subsection{Settings and sampling}

In order to test the hypotheses outlined above, data were collected across four different settings reflecting the structure FCB grid. The products selected as research contexts for our study are soft drinks (low involvement, feel), toothpaste (low involvement, think), day cream (high involvement, feel) and DVD players (high involvement, think). To enhance the external validity of our research, data were collected using one of the largest marketing research panels in Belgium.

\subsection{Questionnaire design}

We opted to construct 16 different questionnaires (i.e., collected from 16 different [sub]samples), so that each questionnaire assesses one value measurement method in one setting. All questionnaires were identical in terms of the measurement instruments for customer word of mouth intentions and the manipulation checks (i.e., measurement of involvement and type of offering). What differed across the questionnaires was the value measurement method employed which, furthermore, needed to be adapted to the particular setting. The contents of the questionnaires as well as a detailed explanation of how the different customer value measurement methods were operationalized can be found in LeroiWerelds et al. (2014). Data collection continued until we obtained an effective sample size of 210 for each of the 16 questionnaires (i.e., setting-method combinations).

\subsection{Analytical approach}

All analyses were performed using smartPLS 2.0 M3 (Ringle, Wende, \& Will, 2005). To assess the statistical significance of parameter estimates and differences in parameter estimates we constructed bootstrap percentile confidence intervals based on $\mathrm{J}=5,000$ (cf. Preacher \& Hayes 2008).

\subsection{Measurement model structure and properties}

Following the work of Jarvis, MacKenzie, and Podsakoff (2003), the measurement model structures for the four customer value measurement approaches used in this study are specified as follows. The scale suggested by Dodds et al (1991) was modeled as reflective first-order model. A first-order formative model was used to operationalize Gale's (1994) approach. Here, the constructed market-perceived price and market-perceived quality scores act as formative indicators.

For the remaining two methods (i.e., Woodruff and Gardial (1996), Holbrook (1999)) we specified second-order measurement models. For the Woodruff and Gardial (1996) approach, overall value is a second order construct formed by two first-order constructs (i.e., benefits and sacrifices). In turn, the benefit construct is modeled as a formative construct and the sacrifice construct is modeled as a reflective construct. Regarding Holbrook's (1999) approach, overall value represents a second-order construct with the dimensions arising from his typology acting as first order constructs that form overall value. The various first-order constructs are either formative or reflective in nature. For more details regarding the exact measurement model specifications, which reflects the theoretical foundations of the respective value measurement approaches, the reader is referred to Leroi-Werelds et al (2014).To model 
customer value as a second-order construct, we used the two-stage approach (Reinartz, Krafft \& Hoyer, 2004) wherein, in the first stage, the latent variable scores were estimated without the second-order construct (customer value) present but with all of the first-order constructs (benefits and sacrifices) in the model. In the second stage, the latent variable scores of the first-order factors (benefits and sacrifices) were used as indicators of the second-order construct (customer value) in a separate higher-order PLS model.

We first examined the psychometric properties of all first-order constructs used in our study. In terms of psychometric properties, it is crucial to distinguish between reflective and formative scales (MacKenzie, Podsakoff \& Jarvis 2005). Regarding the reflective scales, we assessed unidimensionality (procedure Sahmer, Hanafi and El Qannari (2006) and cut-off criteria proposed by Karlis, Saporta, and Spinakis (2003)), internal consistency reliability (procedure Jöreskog (1971)), item validity (procedure Hulland (1999)), within-method convergent validity and discriminant validity (procedure Fornell and Larcker 1981). Regarding the formative constructs we assessed the statistical significance of the items (cf. Diamantopoulos \& Winklhofer, 2001) and to evaluate discriminant validity we assessed whether the latent variable correlations fall within two standard errors of an absolute value of 1 (MacKenzie et al., 2005). Detailed results regarding the constructs' psychometric properties can be found in Leroi-Werelds et al. (2014). All constructs possess favorable properties with exception of the value measurement method proposed by Dodds et al. (1991). Consequently, the Dodds et al. (1991) value measurement approach will be left out of the remaining analyses.

\subsection{Testing the FAC-SEM hypotheses}

Relative performance is indicated by the difference in predictive ability of two methods. The predictive ability is measured by the coefficient of multiple correlation $R$. In general terms the parameter of interest can be expressed as presented in Equation 1.

$$
\Delta_{p q}=R_{p}-R_{q}(\mathrm{p} \neq \mathrm{q})
$$

Where:

$\Delta_{p q} \quad=\quad$ Difference in predictive ability between value measurement methods $\mathrm{p}$ and $\mathrm{q}$

$R_{p} \quad=\quad$ Predictive ability value measurement method $\mathrm{p}$

$R_{q} \quad=\quad$ Predictive ability value measurement method $\mathrm{q}$

In the context of the current study, this leads to the following parameters of interest: $\Delta_{W G}=R_{W}-R_{G}$ and $\Delta_{H G}=R_{H}-R_{G}$, which, respectively, assess the relative performance of Woodruff and Gardial's (1996) and Holbrook's (1999) method versus Gale's (1994) approach. Although we did not posit hypotheses for the differences in relative performance between Holbrook's (1999) and Woodruff and Gardial's (1996) method, we also compared these methods for reasons of completeness. This captured by parameter $\Delta_{H W}=R_{H}-R_{W}$. The different FAC-SEM hypotheses are presented below in Table 3.

As outlined in paragraph 2.2 FAC-SEM analysis requires combining the data from different cells in the factorial design. For example, to assess the main effect of involvement, we needed to merge the data from the high involvement settings and compare them with the merged data from the low involvement settings. This is challenging as for the methods of Gale, Woodruff and Gardial, and Holbrook different items (i.e., variables) are used across the settings. To overcome this, we proceeded as follows to arrive at a structural model that was identical for all methods and across all settings. We started with estimating twelve (4 settings and 3 methods because Dodds et al. 1991 was not taken into account) structural models in 
which $y=f$ (perceived customer value). We then used the estimation results to obtain the predicted values $(\hat{y})$. These predicted values were subsequently regressed to the actual data (i.e., the latent variable scores) on the outcome variables $y$. Put differently, we estimate the following structural model: $y=f(\hat{y})$. The resulting path coefficient equals the coefficient of multiple correlation $R$ and indicates the models predictive ability. This approach ensures that we have an equal data structure for each of the twelve setting-method combinations was allowing us to construct the merged data files needed to examine the different FAC-SEM hypotheses.

\subsection{Results}

Below we discuss the results of our FAC-SEM analysis per pair of methods. Similar to nway ANOVA, we start our interpretation with the highest-order statistically significant interaction (cf. Keppel 1991). The results of the FAC-SEM analysis are presented in Table 4. The accompanying relative performance statistics as well as the differences in relative performance across the different cells can be derived from Table 2.

Table 3: Overview of the study's FAC-SEM hypotheses

\begin{tabular}{ll}
\hline Woodruff and Gardial vs. Gale \\
\hline Main effect involvement (H1) & $H_{0}: \Delta_{W G(\text { High })} \leq \Delta_{W G(\text { Low })}$ \\
& $H_{A}: \Delta_{W G(\text { High })}>\Delta_{W G(\text { Low })}$ \\
Main effect think/feel (H2) & $H_{0}: \Delta_{W G(\text { Feel })} \leq \Delta_{W G(\text { Think })}$ \\
& $H_{A}: \Delta_{W G(\text { Feel })}>\Delta_{W G(\text { Think })}$ \\
& $H_{0}:\left(\Delta_{W G(\text { Feel })}-\Delta_{W G(\text { Think })}\right)_{\text {High }} \leq\left(\Delta_{W G(\text { Feel })}-\Delta_{W G(\text { Think })}\right)_{\text {Low }}$ \\
Interaction effect (H3) & $H_{A}:\left(\Delta_{W G(\text { Feel })}-\Delta_{W G(\text { Think })}\right)_{\text {High }}>\left(\Delta_{W G(\text { Feel })}-\Delta_{W G(\text { Think })}\right)_{\text {Low }}$
\end{tabular}

Holbrook vs. Gale

Main effect involvement (H1)

$H_{0}: \Delta_{H G(H i g h)} \leq \Delta_{H G(\text { Low })}$

$H_{A}: \Delta_{H G(H i g h)}>\Delta_{H G(\text { Low })}$

Main effect think/feel (H2)

$H_{0}: \Delta_{H G(\text { Feel })} \leq \Delta_{H G(\text { Think })}$

$H_{A}: \Delta_{H G(\text { Feel })}>\Delta_{H G(\text { Think })}$

Interaction effect $(\mathrm{H} 3)$

$H_{0}:\left(\Delta_{H G(\text { Feel })}-\Delta_{H G(\text { Think })}\right)_{H i g h} \leq\left(\Delta_{H G(\text { Feel })}-\Delta_{H G(\text { Think })}\right)_{\text {Low }}$

$H_{A}:\left(\Delta_{H G(\text { Feel })}-\Delta_{H G(\text { Think })}\right)_{H i g h}>\left(\Delta_{H G(\text { Feel })}-\Delta_{H G(\text { Think })}\right)_{\text {Low }}$

\section{Holbrook vs. Woodruff and Gardial}

Main effect involvement (H1)

$H_{0}: \Delta_{H W(H i g h)}=\Delta_{H W(\text { Low })}$

$H_{A}: \Delta_{H W(H i g h)} \neq \Delta_{H W(\text { Low })}$

Main effect think/feel (H2)

$H_{0}: \Delta_{H W(\text { Feel })}=\Delta_{H W(\text { Think })}$

$H_{A}: \Delta_{H W(\text { Feel })} \neq \Delta_{H W(\text { Think })}$

Interaction effect (H3)

$H_{0}:\left(\Delta_{H W(F e e l)}-\Delta_{H W(\text { Think })}\right)_{H i g h}=\left(\Delta_{H W(F e e l)}-\Delta_{H W(\text { Think })}\right)_{\text {Low }}$

$H_{A}:\left(\Delta_{H W(\text { Feel })}-\Delta_{H W(\text { Think })}\right)_{H i g h} \neq\left(\Delta_{H W(\text { Feel })}-\Delta_{H W(\text { Think })}\right)_{\text {Low }}$

Woodruff and Gardial (1996) vs. Gale (1994). A significant interaction effect is found meaning that the difference in relative performance between Woodruff and Gardial (1996) and 
Gale's (1994) methods for feel and think products depends on the level of involvement. In particular, we find that for high involvement settings the magnitude of the relative performance is different for feel and think offerings, whereas this is not the case for low involvement settings.

Holbrook (1999) vs. Gale (1994). Focusing on the difference in relative performance between the methods of Holbrook (1999) and Gale (1994) in explaining word-of-mouth we also find a significant interaction effect. We find that for high involvement settings the magnitude of the relative performance of Holbrook and Gale is different for feel and think offerings, but this is not the case for low involvement settings.

Table 4: FAC-SEM empirical results

\begin{tabular}{|c|c|c|c|}
\hline & $\begin{array}{c}\text { Woodruff and Gardial } \\
\text { vs. } \\
\text { Gale }\end{array}$ & $\begin{array}{c}\text { Holbrook } \\
\text { vs. } \\
\text { Gale } \\
\end{array}$ & $\begin{array}{c}\text { Holbrook } \\
\text { vs. } \\
\text { Woodruff and Gardial }\end{array}$ \\
\hline $\begin{array}{c}\text { Interaction effect } \\
\text { involvement } * \text { think/feel }\end{array}$ & $\rightarrow$ Think & Low & $\mathrm{ns}$ \\
\hline $\begin{array}{l}\text { Main effect involvement } \\
\text { Main effect think/feel } \\
\text { Summary hypotheses tests }\end{array}$ & $\begin{array}{c}\mathrm{ns} \\
\mathrm{ns} \\
\text { H3 supported } \\
\text { (disordinal interaction) }\end{array}$ & $\begin{array}{c}\text { ns } \\
\text { ns } \\
\text { H3 supported } \\
\text { (disordinal interaction) }\end{array}$ & $\begin{array}{c}{[-.31 ;-.06]} \\
\text { ns } \\
\text { H1 supported }\end{array}$ \\
\hline
\end{tabular}

Holbrook (1999) vs. Woodruff (1996). As mentioned before, we also examine whether the difference in performance between the methods of Holbrook (1999) and Woodruff and Gardial (1996) varies as a function of the underlying factorial design for reasons of completeness. As this additional analysis has a mere descriptive purpose, we continue by addressing the relative performance of the two methods for each of the four cells of our factorial design when the FAC-SEM analysis yields significant effects.

For word-of-mouth, we find a significant main effect for involvement: the difference in predictive ability between Holbrook's and Woodruff's method is significantly larger for low involvement settings than for high involvement settings.

Our second research objective was based on the expectation that the relative ability of the different value measurement methods to predict outcome variables, such as satisfaction and loyalty, depends on customer characteristics and product characteristics. This expectation was fueled by the different conceptual perspectives underlying the value measurement methods (see Table 1) as well as on the findings of research objective 1 (see Table 6). Although several interaction effects were statistically significant, the findings for our second research objective suggest that no structural pattern can be discerned among the differences in predictive ability.

\section{Conclusion}

The aim of this paper was to demonstrate how Iacobucci's et al. (2003) FAC-SEM approach that was originally designed for covariance-based structural equation modeling can be applied in a PLS-SEM context. The value of the FAC-SEM approach lies in its capability 
to explain experimental data into greater depth. More specifically, the factorial design underlying the FAC-SEM approach allows researcher to assess differences in parameters due to the factors both in isolation (main effects) and in combination (interaction effect). Where ANOVA techniques only allow assessing mean differences arising from factorial designs, FAC-SEM extends this also offering the possibility to assess the effects of a factorial design on the structural model parameters. Empirical data from a study on customer value measurement was used to illustrate the practical application of the FAC-SEM approach in PLS-SEM.

\section{References}

Claeys, C., Swinnen, A., \& Abeele, P. V. (1995). Consumer's means-end chains for "think" and "feel" products. International Journal of Research in Marketing, 12(3), 193-208.

Dodds, W. B., Monroe, K. B., \& Grewal, D. (1991). Effects of price, brand, and store information on buyers' product evaluations. Journal of marketing research, 307-319.

Diamantopoulos, A., \& Winklhofer, H. M. (2001). Index construction with formative indicators: An alternative to scale development. Journal of marketing research, 38(2), 269-277.

Fornell, C., \& Larcker, D. F. (1981). Structural equation models with unobservable variables and measurement error: Algebra and statistics. Journal of marketing research, 382388.

Gale, B. T. (1994). Managing customer value (Vol. 29). New York: The Free Press.

Gutman, J. (1982). A means-end chain model based on consumer categorization processes. Journal of Marketing, 46 60-72.

Holbrook, M. B. (Ed.). (1999). Consumer value: a framework for analysis and research. Psychology Press.

Hulland, J. (1999). Use of partial least squares (PLS) in strategic management research: A review of four recent studies. Strategic management journal, 20(2), 195-204.

Iacobucci, D., Grisaffe, D., Duhachek, A., \& Marcati, A. (2003). FAC-SEM: a methodology for modeling factorial structural equations models, applied to cross-cultural and crossindustry drivers of customer evaluations. Journal of Service Research, 6(1), 3-23

Jarvis, C. B., MacKenzie, S. B., \& Podsakoff, P. M. (2003). A critical review of construct indicators and measurement model misspecification in marketing and consumer research. Journal of consumer research, 30(2), 199-218.

Jöreskog, K. G. (1971). Statistical analysis of sets of congeneric tests. Psychometrika, 36(2), 109-133.

Karlis, D., Saporta, G., \& Spinakis, A. (2003). A simple rule for the selection of principal components. Communications in Statistics-Theory and Methods, 32(3), 643-666.

Keppel, G. (1991). Design and analysis: A researcher's handbook. Prentice-Hall, Inc.

Leroi-Werelds, S., Streukens, S., Brady, M. K., \& Swinnen, G. (2014). Assessing the value of commonly used methods for measuring customer value: a multi-setting empirical study. Journal of the Academy of Marketing Science, 42(4), 430-451.

MacKenzie, S. B., Podsakoff, P. M., \& Jarvis, C. B. (2005). The problem of measurement model misspecification in behavioral and organizational research and some recommended solutions. Journal of Applied Psychology, 90(4), 710.

Mulvey, M. S., \& Olson, J. C. (1994). Exploring the relationship between means-end knowledge and involvement. Advances in Consumer Research, 21(1), 51-57.

Preacher, K. J., \& Hayes, A. F. (2008). Asymptotic and resampling strategies for assessing and 
comparing indirect effects in multiple mediator models. Behavior research methods, 40(3), 879-891.

Ratchford, B. T. (1987). New insights about the FCB grid. Journal of advertising research, 27(5), 24-38.

Reinartz, W., Krafft, M., \& Hoyer, W. D. (2004). The customer relationship management process: Its measurement and impact on performance. Journal of marketing research, 41(3), 293-305.

Ringle, C. M., Wende, S., \& Will, S. (2005). SmartPLS 2.0 (M3) Beta, Hamburg.

Sahmer, K., Hanafi, M., \& El Qannari, M. (2006). Assessing unidimensionality within PLS path modeling framework. In From data and information analysis to knowledge engineering (pp. 222-229). Springer Berlin Heidelberg.

Sanchez-Fernandez, R., Iniesta-Bonillo, M., \& Holbrook, M. B. (2009). The conceptualization and measurement of customer value in services. International Journal of Marketing Research, 15(1), 93-113.

Sarstedt, M., Henseler, J., \& Ringle, C. M. (2011). Multigroup analysis in partial least squares (PLS) path modeling: Alternative methods and empirical results. Advances in International Marketing, 22(1), 195-218.

Slater, S. F. (1997). Developing a customer value-based theory of the firm. Journal of the Academy of marketing Science, 25(2), 162-167.

Woodruff, R. B., \& Gardial, S. (1996). Know your customer: New approaches to understanding customer value and satisfaction. Wiley.

Zeithaml, V. A. (1988). Consumer perceptions of price, quality, and value: a means-end model and synthesis of evidence. The Journal of marketing, 2-22. 